\title{
O uso variável do imperativo de migrantes baianos em São Paulo ${ }^{1}$
}

\author{
The variable use of the imperative of Bahian migrants in São Paulo
}

Emerson Santos de Souza*

\begin{abstract}
RESUMO: O imperativo, no português brasileiro, apresenta duas principais formas em variação: uma com morfologia de subjuntivo, ex.: “Traga o carro!", e outra com morfologia de indicativo, ex.: “Traz o carro!” (SCHERRE, 2004). Oliveira (2015), a partir dos dados do ALiB (CARDOSO et al., 2014), mostrou a diferença de uso dessas formas entre Bahia e São Paulo, sendo que, em Salvador, a forma predominante é a subjuntiva (77 \%), enquanto em São Paulo, é a indicativa (86\%). Este artigo analisa o uso do imperativo por baianos em São Paulo, partindo-se da hipótese de que tais migrantes aumentariam a proporção de uso da forma indicativa. A regressão logística de efeitos mistos, feita no R (R CORE TEAM, 2018), a partir do corpus formado por respostas de um questionário on-line aplicado a baianos em São Paulo (FIGUEREIDO; SOUZA, 2017), evidencia o aumento significativo do uso da forma indicativa pelos migrantes e sugere que ela ocorre mais: entre os menos escolarizados; entre os que migraram quando adultos; entre os que estão em São Paulo há menos tempo; em

ABSTRACT: The imperative, in Brazilian Portuguese, presents two main forms in variation: one with subjunctive morphology, e.g.: "Traga o carro!", and another with indicative morphology, e.g.: "Traz o carro!" 'Bring the car!' (SCHERRE, 2004). Oliveira (2015), based on data from ALiB (CARDOSO et al., 2014), showed the difference between Bahia and São Paulo in the usage of these forms, since in Salvador the predominant form is the subjunctive $(77 \%)$, while in São Paulo, it is the indicative $(86 \%)$. This article analyzes the use of the imperative by Bahians in São Paulo, starting from the hypothesis that such migrants would increase the proportion of usage of the indicative form. The mixed effects logistic regression in R (CORE TEAM, 2018) of the answers to an online questionnaire applied to Bahians in São Paulo (FIGUEREIDO; SOUZA, 2017), shows a significant increase in the use of the indicative by the migrants and suggests that it occurs more among the less educated; those who migrated as adults; who have been in São Paulo less time; in the context of asymmetric interpersonal
\end{abstract}

\footnotetext{
${ }^{1}$ Este trabalho é resultado do refinamento dos dados apresentados no VII Encontro de Sociolinguística: Redes e Contato, realizado na Universidade Federal de Sergipe, em Aracaju-SE, em 2017.

* Doutorando em Linguística pelo Programa de Pós-graduação em Linguística do Instituto de Estudos da Linguagem - IEL, da Universidade Estadual de Campinas - Unicamp. https://orcid.org/0000-00034123-0788. souza.emersonsantos@hotmail.com.
} 
contexto de relações interpessoais assimétricas; em situações de ordem e pedidos (em contraste a conselhos e instruções); em contextos imediatos; e em sentenças afirmativas.

PALAVRAS-CHAVE: Imperativo. Contato dialetal. Migrantes baianos. Português paulista. Português baiano. relations; in situations of order and requests (in contrast to advice and instructions); in immediate contexts; and in affirmative sentences.

KEYWORDS: Imperative. Dialect contact. Bahian migrants. São Paulo Portuguese. Bahian Portuguese.

\section{Introdução}

No português brasileiro, o modo imperativo apresenta duas principais formas em variação: uma com morfologia de subjuntivo, como em “Traga o carro!”, e outra com morfologia de indicativo, como em “Traz o carro!" (SCHERRE, 2004). A partir dos dados do Projeto Atlas Linguístico do Brasil - ALiB (CARDOSO et al., 2014), Oliveira (2015)² evidenciou que o uso dessa última variante em relação àquela é mais comum no Centro-Oeste, Norte, Sudeste e Sul em comparação ao Nordeste.

Seus resultados mostraram, por exemplo, que a variante prototípica da cidade de São Paulo - SP é o imperativo com morfologia de indicativo, com 86 \% das ocorrências e peso relativo de .75 em relação às demais capitais do Sudeste, enquanto a variante prototípica de Salvador - BA é o imperativo com morfologia de subjuntivo, uma vez que os resultados apontaram $23 \%$ de uso e .11 de peso relativo para o uso do imperativo com morfologia de indicativo em relação a outras capitais nordestinas.

Esses dados sugerem que o uso variável do imperativo é um traço morfossintático que diferencia o dialeto paulista do dialeto baiano, cujo contato poderia gerar mudanças linguísticas, sobretudo, na fala dos migrantes. Trudgill (1986), baseado na Teoria da Acomodação (GILES et al., 1973), sugere que as mudanças ocasionadas do contato entre dialetos mutuamente inteligíveis acontecem devido à

\footnotetext{
2 Agradeço a professora Josane Oliveira por compartilhar os slides da apresentação realizada no XII Workshop do Projeto Atlas Linguístico do Brasil, na Universidade Federal da Bahia, em Salvador - BA, em 2015.
} 
convergência positiva dos migrantes para com a comunidade anfitriã. Esses efeitos, segundo Chambers (1992), podem ser notados em diferentes níveis linguísticos, a saber, no fonético-fonológico, no morfossintático, no lexical e no pragmático.

Ao assumir isso, pode-se levantar a hipótese de que um baiano, ao migrar para São Paulo, aumentaria a proporção de uso da forma indicativa por influência da comunidade anfitriã. Se este for o caso, é pertinente questionar quais seriam os fatores sociais e linguísticos que contribuiriam para que essa variante fosse mais usada pelos migrantes do que por aqueles que permanecem em sua comunidade de origem. A fim de responder a esses questionamentos, objetiva-se, neste trabalho, (i) analisar se há diferença significativa entre as realizações do imperativo com morfologia de indicativo entre baianos residentes em São Paulo e de baianos residentes na Bahia e (ii) correlacionar variáveis previsoras (sociais e linguísticas) aos usos do imperativo a fim de observar os padrões de realização dessa variável no comportamento linguístico dos migrantes baianos em São Paulo.

Em razão da dificuldade de capturar as formas imperativas em entrevistas sociolinguísticas, aplicou-se um questionário on-line, baseado em Nunes e Schwenter $(2015)^{3}$, a baianos residentes na Bahia e a migrantes baianos em São Paulo, recrutados, de maneira semialeatória ${ }^{4}$, através de mídias sociais como Facebook, Instagram e WhatsApp. Os dados obtidos foram submetidos a testes estatísticos em análises de regressão logística de efeitos mistos com inclusão do informante e do verbo como variáveis aleatórias na plataforma R (R CORE TEAM, 2018), e de variáveis previsoras sociais (Escolaridade, Idade de Migração, Tempo em São Paulo, Tipo de Relação) e linguísticas (Intenção Comunicativa, Contexto Temporal e Polaridade).

\footnotetext{
${ }^{3}$ Agradeço a Luana Nunes e a Scott Schwenter por disponibilizar os slides apresentados no $44^{\circ}$ NWAV, realizado em Toronto-CA, em 2015.

${ }^{4}$ Entende-se por abordagem semialeatória aquela em que há certo grau de interferência do pesquisador durante o recrutamento dos participantes.
} 
De modo geral, os resultados indicam haver uma diferença significativa entre a escolha da forma indicativa dos baianos residentes em São Paulo, em relação àqueles baianos que não migraram de sua comunidade nativa. Além disso, apontam que o aumento da proporção de uso da forma indicativa ocorre mais entre: os falantes menos escolarizados, com até o nível médio; os que migraram quando adultos; os que estão em São Paulo há até 7 anos e em contextos cuja relação entre os interlocutores é assimétrica. Os resultados ainda mostram que os falantes com esses perfis usam mais essa variante em situações cujas intenções são de ordenar e pedir (em relação a aconselhar e instruir), em ações a ser realizadas em contextos imediatos e em sentenças que têm polaridade afirmativa.

Essas informações são descritas ao longo deste artigo. Assim sendo, este texto está subdividido em 4 seções, além dessa parte introdutória. Na primeira delas, resenham-se os trabalhos que trataram do uso variável do imperativo de falantes nativos em diferentes comunidades, como Scherre (2004), Oliveira (2015, 2017), Nunes e Schwenter (2015) e, no comportamento linguístico de migrantes, como Cardoso (2009); além de uma breve discussão acerca do contato entre dialetos mutuamente inteligíveis, a partir de Trudgill (1986), Chambers (1992) e Siegel (2010). Em seguida, detalha-se o passo a passo de como ocorreram a coleta e o tratamento dos dados. Na seção subsequente, apresentam-se os resultados das análises dos modelos estatísticos da regressão logística de efeitos mistos que testaram a correlação entre a variável resposta e as variáveis previsoras sociais e linguísticas. Por fim, fazem-se as considerações finais.

\section{Pressupostos teóricos}

Como visto, no português brasileiro, há duas principais formas imperativas: uma com morfologia de subjuntivo e outra com morfologia de indicativo. De acordo com Scherre (2004), no Brasil, aquela forma é mais prototípica da Região Nordeste, 
enquanto esta é mais recorrente nas Regiões Sul, Sudeste e Centro-Oeste. Para a Região Norte, que até então não havia sido mapeada quanto ao uso dessa variável, Scherre (2004) conjecturou que haveria um "alinhamento" com a Região Nordeste, i.e., ambas as regiões que estão mais ao norte do Brasil usariam o imperativo com morfologia de subjuntivo.

A fim de mapear o uso variável do imperativo nas 25 capitais brasileiras ${ }^{5}$ que constam no Projeto Atlas Linguístico do Brasil - ALiB (Cardoso et al., 2014), Oliveira (2015) analisou um corpus constituído por 200 informantes (8 de cada capital), estratificados em Sexo (100 homens e 100 mulheres), Faixa Etária (Faixa I: 18-30 anos e Faixa II: 50-65 anos) e Escolaridade (Fundamental e Superior). A distribuição geral do total de 2535 ocorrências mostrou que $65 \%$ é da forma indicativa, de modo que os informantes têm usado mais o modo imperativo com morfologia de indicativo do que a forma de subjuntivo.

Numa análise por região, nota-se que, diferentemente do que previu Scherre (2004), a Região Norte (42,50 \%), com exceção de Porto Velho (.39), assemelha-se às Regiões Centro-Oeste (46,1 \%), Sudeste (46,1\%) e Sul (43,60 \%), salvo Curitiba (.42), quanto ao uso da forma indicativa. Já a Região Nordeste (26,63 \%), à exceção de São Luís (.52), teve a predominância do imperativo com a forma de subjuntivo.

Numa observação pormenorizada, Oliveira (2017) verificou o emprego do imperativo associado ao indicativo no Nordeste. Com base em 72 inquéritos do ALiB (Cardoso et al., 2014), ela angariou 753 dados de imperativo, dos quais 233 são da forma indicativa (31 \%) e 520 da forma subjuntiva (69\%). A análise estatística feita no GoldVarbX apontou como relevantes as variáveis Cidade, Polaridade da Sentença e Paradigma Verbal. A correlação com a variável Cidade, especificamente, mostrou que São Luís (.84) e Fortaleza (.66) favorecem o indicativo, Teresina (.50) e Recife (.49) ficam

\footnotetext{
${ }^{5}$ De acordo com um dos critérios da Projeto ALiB (Cardoso et al., 2014), Palmas - TO e Brasília não fariam parte da coleta de dados por terem sua fundação recente.
} 
próximas da média geral da região, enquanto Maceió (.46), João Pessoa (0.41), Salvador (0.41), Aracaju (0.41) e Natal (.27) desfavoreceram o seu uso.

Para elucidar o uso das formas imperativas em cidades das Regiões Sudeste e Sul, Nunes e Schwenter (2015) aplicaram um questionário on-line a paulistas e gaúchos recrutados através de mídias sociais. Esse instrumento de coleta é formado por 30 questões organizadas e balanceadas, sobretudo, de acordo com a variável Polaridade, sendo 12 perguntas com forma imperativa afirmativa, 12 com forma negativa e mais 6 distratores. A cena descrita em cada questão conduzia os participantes a escolher umas das duas formas imperativas, indicativa ou subjuntiva.

Com esse método, Nunes e Schwenter (2015) coletaram 4.272 dados dessa variável sociolinguística. O resultado geral, obtido a partir da análise de regressão logística feita na plataforma $\mathrm{R}$, mostrou que, em ambas as comunidades, há a prevalência da forma indicativa em relação à subjuntiva; que a polaridade afirmativa desfavorece o imperativo com forma de subjuntivo (logodds -1.6732) em relação à polaridade negativa e que o contexto não-imediato (2.2248) favorece o uso do imperativo com forma de subjuntivo em relação ao contexto imediato.

Os estudos anteriormente arrolados sugerem que o uso variável do imperativo é um traço morfossintático que diferencia os falares do Nordeste em comparação aos dialetos das outras regiões brasileiras. Assumir isso permite levantar a hipótese de que se uma pessoa do Nordeste migrar para alguma cidade das demais regiões do Brasil, possivelmente aumentará sua proporção de uso do imperativo com morfologia de indicativo, já que a migração pode ser um dos fatores que contribuem para as mudanças na fala do indivíduo.

Segundo Trudgill (1986), a mudança linguística gerada a partir do contato entre dialetos mutuamente inteligíveis ocorre por causa da convergência positiva (ver GILES et al., 1973) do migrante para com a comunidade anfitriã. Essas mudanças, de 
acordo com Chambers (1992), podem atingir os distintos níveis linguísticos, como o fonético-fonológico, o morfossintático, o lexical e o pragmático.

Os efeitos do contato dialetal na fala dos migrantes podem ser observados, de acordo com Siegel (2010), por meio de duas principais perspectivas: pela análise da fala do migrante em diferentes momentos de sua estada na comunidade anfitriã ou pela comparação feita entre a fala dos migrantes e amostras-controle da comunidade de origem e da comunidade anfitriã, a fim de perceber se o percentual de uso de determinado fenômeno linguístico da fala do migrante se aproxima dos usos desta ou daquela comunidade. Por causa do fato das áreas dialetais brasileiras se distinguirem, muitas vezes por causa da discrepância da proporção de uso de determinadas variáveis sociolinguísticas, como o uso variável das formas imperativas, escolhe-se esse último tipo de análise.

Cardoso (2009), por exemplo, analisou a fala de fortalezenses residentes em Brasília, comunidade em que predomina o uso do imperativo com forma de indicativo. De um corpus formado por 16 informantes, a autora obteve o total de 972 dados de imperativo, dos quais $68 \%$ correspondiam à forma indicativa em relação à variante subjuntiva. Esses dados foram eliciados por meio de cenas de quadrinhos com situações diretivas, para os quais a autora solicitava aos participantes que dissessem o que falariam naquelas situações. Ao comparar esse resultado com os valores percentuais de realização da forma indicativa de dois grupos controle, um de fortalezenses não migrantes, que apresentou o total de $40 \%$ de uso dessa variante, e outro de brasilienses, que teve 90 \% de realização da mesma variante, Cardoso (2009) observou que os fortalezenses no Distrito Federal tendem a assimilar a variante imperativa mais prototípica da comunidade anfitriã.

O presente trabalho também se volta à análise dos padrões linguísticos de migrantes, cuja metodologia se descreve a seguir. 


\section{Metodologia}

Figuereido e Souza (2017), baseados em Nunes e Schwenter (2015), elaboraram um questionário virtual no Google Forms a fim de constituir dois corpora, um com participantes baianos em São Paulo e outro de baianos residentes na Bahia, com o objetivo de comparar o uso do imperativo com morfologia de indicativo entre essas duas comunidades e investigar quais possíveis variáveis sociais e linguísticas motivariam a sua realização. O questionário é formado por 30 estímulos, 14 distratores e 16 sentenças-alvo, que foram elaboradas a partir do cruzamento de contextos linguísticos observados em outras pesquisas: Polaridade (afirmativa/negativa) (SCHERRE, 2003, 2004; OLIVEIRA, 2017; NUNES; SCHWENTER, 2015); Contexto Temporal (imediato/não-imediato) (NUNES; SCHWENTER, 2015); e Intenção Comunicativa (aconselhar, instruir, pedir e ordenar). As cenas descritas em cada sentença-alvo foram projetadas na tentativa de simular uma situação quotidiana na qual o informante fosse conduzido a escolher uma das duas formas imperativas. Os 16 estímulos-alvo são reproduzidos em (1). Os verbos imperativos aí italicizados, evidentemente, foram apresentados sem destaque aos participantes.

(1)
a. O pai percebe que o filho está mexendo no celular em vez de
- Faça as atividades ou vou tomar seu celular. fazer as atividades escolares. Se
- Faz as atividades ou vou tomar seu celular. seu filho?
b. Você é um(a) professor(a) que $\rightarrow \quad \circ$ Traz a maquete na próxima semana ou solicitou aos alunos uma maquete como atividade avaliativa da unidade, mas um vai ficar com zero.
- Traga a maquete na próxima semana ou vai ficar com zero. aluno esqueceu de trazê-la. 
c. Você é pai (mãe) super protetor(a) e não vai deixar seu filho ir à festa de final de ano que a turma está programando. Como diria isso ele?

d. Você é um(a) professor(a) que não tolera atrasos e um aluno chega 30 minutos após a aula ter começado. O que diria a ele?

e. Você foi ao salão cortar as pontas do cabelo, mas a cabeleireira é famosa por cortar mais do que as clientes pedem. Como você pediria para ela não fazer isso com seu cabelo?

f. Você está prestes a viajar e não está com tempo de arrumar a sua mala. Como você diria para sua filha fazer isso por você?

g. Você se esqueceu de comprar os ovos para fazer o bolo e lembra que seu filho está na rua. Ao ligar pra ele, como você pediria pra ele trazer?

h. Você levou seu computador para formatar, mas só poderá pegar dois dias depois. Você está com receio de o funcionário se esquecer de fazer o serviço. Como você diria para ele?

i. Julia se casou e é péssima na cozinha. Então ela pede ajuda à mãe dela para preparar um simples arroz. Se você fosse a mãe de Julia, com ensinaria? $\rightarrow \quad$ o Não vai à festa!

- Não vá à festa!

$\rightarrow \quad \circ$ Não entra na sala, espera a próxima aula começar!

- Não entre na sala, espere a próxima aula começar!

$\rightarrow \quad \circ$ Não corte muito, apenas as pontas.

- Não corta muito, apenas as pontas.

$\rightarrow \quad \circ$ Filha, por favor, arrume minha mala.

- Filha, por favor, arruma minha mala.

$\rightarrow \quad \circ$ Quando vier pra casa, compre ovos pro bolo.

- Quando vier pra casa, compra ovos pro bolo.

○ Por favor, não se esqueça de formatar o meu computador.

- Por favor, não se esquece de formatar o meu computador.

$\rightarrow \quad$ o Filha, é fácil! Coloca o arroz em uma panela com água e sal e espera cozinhar.

- Filha, é fácil! Coloque o arroz em uma panela com água e sal e espere cozinhar. 
j. Você está ensinando seu irmão a conectar a TV pela primeira vez. Como você o instruiria?

1. Maria está nervosa, pois vai fazer um prato especial pro maridão para comemorar $\mathrm{o}$ primeiro ano de casados. Se você fosse amiga de Maria, o que lhe diria?

m. Você está estudando com seu filho para uma prova amanhã. Como você diria para ele não se esquecer de preencher o cabeçalho?

n. Sua amiga tirou carteira de habilitação e está prestes a viajar, mas tem muito medo de dirigir em uma BR. Que conselho lhe daria?

o. Sua amiga se preocupa muito com a opinião das outras pessoas e, por isso, evita fazer coisas que a sociedade condene. Que conselho você daria para ela?

p. Você está aplicando uma prova de Matemática e percebe que um aluno está bastante agitado em sua carteira, tentando olhar para prova do colega ao lado. O que lhe diria?

q. Você é um(a) tio(a) que se preocupa bastante com seu sobrinho e percebe que ele anda fazendo coisas erradas. Que conselho daria para ele? $\rightarrow \quad$ ○ Não liga a TV na tomada antes de montar ela.

- Não ligue a TV na tomada antes de montar ela.

$\rightarrow \quad \circ \quad$ Vai ser lindo! Não fique nervosa!

- Vai ser lindo! Não fica nervosa!

$\rightarrow \quad \circ \quad$ Não deixe o cabeçalho em branco.

- Não deixa o cabeçalho em branco.

$\rightarrow \quad \circ \quad$ Pense que está em uma via calma e tudo vai ficar bem.

- Pensa que está em uma via calma e tudo vai ficar bem.

$\rightarrow \quad$ ○ A vida é curta! Dá menos importância pra essas pessoas!

- A vida é curta! Dê menos importância pra essas pessoas!

$\rightarrow \quad \circ \quad$ Não olhe a prova do colega pra que você não seja reprovado!

- Não olha a prova do colega pra que você não seja reprovado!

$\rightarrow \quad \circ \quad$ Não anda com pessoas ruins.

- Não ande com pessoas ruins. 
Esse instrumento de coleta de dados foi aplicado, de maneira semialeatória, a baianos residentes em Feira de Santana-BA e a migrantes baianos em cidades do estado de São Paulo recrutados por meio de mídias sociais como Facebook, WhatsApp e Instagram. Essa abordagem rendeu a participação de 41 informantes (14 homens e 27 mulheres) na Bahia, perfazendo um total de 656 ocorrências imperativas, e de 34 migrantes baianos (10 homens e 24 mulheres) em São Paulo, dos quais foram obtidas 544 ocorrências de uso do imperativo. São os dados desses últimos que são aqui analisados mais detalhadamente, pelo interesse no comportamento linguístico dos migrantes.

Durante o tratamento dos dados para esta análise, decidiu-se excluir certos dados: (i) dois informantes da amostra de migrantes baianos foram excluídos pelo fato de eles terem chegado a São Paulo com menos de 10 anos de idade e serem os únicos representantes dessa faixa etária de migração e (ii) as sentenças com o verbo "ir" (1c) foram excluídas, porque a cena retratada com esse verbo apresentou ambiguidade e, por causa disso, os resultados podem ter sido enviesados. Assim, este estudo foi realizado a partir das respostas dadas a 15 sentenças-alvo por 73 informantes (41 baianos em seu lugar origem e 32 migrantes baianos em São Paulo).

Pelo método de coleta e recrutamento de participantes on-line, este não é um corpus estratificado, pois não foi possível ter total controle sobre as características sociais dos participantes da amostra. Especificamente os migrantes baianos em São Paulo, principal foco aqui, foram organizados, segundo suas características sociodemográficas, de acordo com os grupos do Quadro 1 a seguir. O principal critério para a definição dos níveis foi o de ter um número balanceado de participantes em cada um deles. 
Quadro 1 - Distribuição dos informantes por perfil sociodemográfico.

\begin{tabular}{|l|c|c|c|l|l|}
\hline \multicolumn{1}{|c|}{ Escolaridade } & $\mathbf{N}$ & Idade de migração & $\mathbf{N}$ & Tempo em São Paulo & $\mathbf{N}$ \\
\hline $\begin{array}{l}\text { Até o Nível } \\
\text { Médio }\end{array}$ & 16 & Faixa I: $13-21$ anos & 12 & Faixa I: 0 - 7 anos & 12 \\
\hline Nível Superior & 16 & Faixa II: $22-24$ anos & 10 & Faixa II: $8-15$ anos & 10 \\
\hline -- & & Faixa III: $25-35$ anos & 10 & Faixa III: $\geq 16$ anos & 10 \\
\hline Total & 32 & -- & 32 & -- & 32 \\
\hline
\end{tabular}

Fonte: elaborado pelo autor.

A análise dos dados foi feita na plataforma R (R CORE TEAM, 2018) em duas etapas. Na primeira, foi realizado um modelo estatístico de regressão logística no conjunto total de dados das duas amostras, a fim de verificar se havia diferença significativa para o uso do imperativo com morfologia de indicativo entre os baianos residentes nas diferentes comunidades. Na segunda etapa, para uma análise mais refinada dos dados dos migrantes baianos e com o propósito de perceber quais fatores estariam correlacionados ao uso do imperativo com morfologia de indicativo, foram aplicados testes de regressão logística de efeitos mistos, com a inclusão do Informante e do Verbo como variáveis aleatórias, ${ }^{6}$ às variáveis previsoras que se descrevem a seguir.

\subsection{Variáveis previsoras sociais}

Com base na literatura do contato entre dialetos mutuamente inteligíveis, controlaram-se as seguintes variáveis previsoras sociais: (i) Escolaridade, com base na hipótese de que, quanto menos escolarizado o falante for, mais características do dialeto anfitrião ele tenderia a adquirir (ALVES, 1979); (ii) Idade de Migração, sob a hipótese de que quanto mais cedo o falante chegar à comunidade anfitriã, mais

\footnotetext{
${ }^{6} \mathrm{O}$ controle desses últimos efeitos permite observar se as correlações são consequências das variáveis fixas ou se são por ocasião de certos indivíduos que se comportam de maneira diferente da população representada (LEVSHINA, 2015; OUSHIRO, 2017b).
} 
características linguísticas dela ele adquiriria (OUSHIRO, 2017a); (iii) Tempo em São Paulo, sob a hipótese de que quanto mais tempo o indivíduo estiver sob os insumos linguísticos da comunidade anfitriã, mais traços ele aprenderia (TRUDGILL, 1986; SIEGEL, 2010; OUSHIRO, 2017a). Adicionalmente, com base no estudo de Dias (2007) sobre a variação entre os pronomes tu e você em Brasília, foi incorporada a este estudo a variável (iv) Tipo de Relação entre as personagens das sentenças, se assimétrica, como entre cabelereira e cliente em (1e); ou simétrica, como entre Maria e sua amiga em (11), a partir da hipótese de que as relações assimétricas favoreceriam o uso do imperativo com forma de indicativo.

\subsection{Variáveis previsoras linguísticas}

A grande maioria das variáveis linguísticas analisadas faz parte de um conjunto de variáveis testadas na literatura sobre o uso variável do imperativo no Brasil: Intenção Comunicativa, aconselhar (11), instruir (1j), pedir (1h) e ordenar (1d), a partir da hipótese de que as situações de ordem e pedido favoreceriam o uso da forma indicativa por serem as situações que podem demostrar mais rispidez; Contexto Temporal, imediato e não-imediato, como em (1e) e (1g) respectivamente, com expectativa de que o contexto imediato favoreceria o uso do imperativo em forma de indicativo (NUNES; SCHWENTER, 2015); Polaridade, negativa e afirmativa, como em (1e) e (1g) respectivamente, sob a hipótese de que as frases afirmativas favoreceriam o uso do imperativo com morfologia de indicativo (SCHERRE, 2003, 2004; OLIVEIRA, 2015, 2017; NUNES; SCHWENTER, 2015).

\section{Resultados}

O uso das variantes imperativas nas duas amostras é variável, com predominância para a realização do imperativo com morfologia de subjuntivo, sendo 
77 \% para os baianos na Bahia e 66 \% para os migrantes baianos em São Paulo (Tabela $1)$.

Tabela 1 - Proporção das variantes imperativas nas duas amostras.

\begin{tabular}{|c|c|c|c|c|c|}
\hline & \multicolumn{2}{|c|}{ Subjuntivo } & \multicolumn{2}{|c|}{ Indicativo } & \multirow[b]{2}{*}{ Frequência geral } \\
\hline Amostra & $\mathbf{N}$ & $\%$ & $\mathbf{N}$ & $\%$ & \\
\hline Baianos na Bahia & 505 & 77 & 151 & 23 & 656 \\
\hline Baianos em São Paulo & 340 & 66 & 172 & 34 & 512 \\
\hline Total & 845 & & 323 & & 1.168 \\
\hline
\end{tabular}

Fonte: elaborado pelo autor.

Na Tabela 1, chama atenção o fato de haver um distanciamento de $11 \%$ no uso do imperativo com morfologia de indicativo dos baianos em São Paulo em relação aos baianos residentes na Bahia. O modelo estatístico de regressão logística, que incluiu a variável social Amostra como efeito fixo e o Informante e o Verbo como efeitos aleatórios, indica que essa diferença é significativa, conforme a Tabela 2. Como o principal objetivo desta pesquisa é saber se os migrantes baianos aumentariam o uso da variante imperativa mais prototípica de São Paulo, durante a aplicação dos modelos estatísticos, reportam-se os resultados para o uso do imperativo com morfologia de indicativo.

Tabela 2 - Resultados da análise de regressão logística em modelo de efeitos mistos para o uso do imperativo com morfologia de indicativo de acordo com as amostras.

\begin{tabular}{lccccc}
\hline & Estimativa & Erro padrão & Valor- $\boldsymbol{z}$ & $\boldsymbol{P}$ & \\
\hline (Intercept) & $-2,0693$ & 0.3425 & -6.042 & $<0,001$ & $* * *$ \\
\hline $\begin{array}{l}\text { Amostra } \\
\text { Baianos em São Paulo }\end{array}$ & 0,7685 & 0,3849 & 1,996 & $<0,05$ & $*$ \\
\hline
\end{tabular}

Modelo: glmer (VD AMOSTRA + (1 I INFORMANTE) + (1 I VERBO), data = dados)

Intercept $=$ Baianos na Bahia.

Fonte: elaborado pelo autor. 
A Tabela 2 tem, na primeira coluna, os níveis da variável independente fixa, Baianos na Bahia e Baianos em São Paulo da variável Amostra. O intercept corresponde ao nível de referência, cujo default, estabelecido pela plataforma $R$, considera a ordem alfabética dos nomes atribuídos a cada nível durante a codificação (nesse caso, o nível de referência é "BA" para Baianos na Bahia). O valor de 0,7685, apresentado na segunda coluna, representa a estimativa em logodds, medida estatística com ponto neutro em zero, cujo valor positivo indica o favorecimento do uso do imperativo com morfologia de indicativo por migrantes baianos em São Paulo em relação ao intercept. Na terceira coluna, o valor de 0,3849 diz respeito ao erro padrão, uma medida de dispersão que mostra a precisão da estimativa. Quanto menor o valor de erro padrão, menor é a variabilidade nas medições (OUSHIRO, 2017b). O valor-z de 1,996, reportado na quarta coluna, é obtido através da razão Estimativa / Erro padrão, a partir do qual provém a medida do valor- $p$ de $<0,05$.

Com o valor de $p<0,05$, a hipótese alternativa que motivou esta pesquisa é acatada. Dito de outra forma, há uma diferença significativa quanto ao uso do imperativo com morfologia de indicativo por baianos em São Paulo em comparação aos baianos que continuam residindo na Bahia. Isso sugere que o uso da forma indicativa por parte dos migrantes sofreu um aumento, presumivelmente por influência dos usos mais frequentes dessa variante na comunidade anfitriã. Casos como esse de assimilação de traços linguísticos da comunidade anfitriã por parte de migrantes são vistos, grosso modo, como uma interferência resultante do contato entre línguas/dialetos (WEINREICH, 1968; THOMASON; KAUFMAN, 1988; WINFORD, 2010).

Esse aumento da proporção de uso do imperativo por baianos residentes em São Paulo pode ter sido motivado especialmente pela escolaridade do migrante, por sua idade de migração, pelo tipo de relação entre os seus interlocutores, pelo tempo de exposição aos insumos linguísticos em São Paulo, pela intenção comunicativa nos 
atos de fala, pelo contexto temporal em que a ação demandada acontece e pela polaridade da sentença, conforme mostram os resultados apresentados na próxima seção.

Duas das variáveis linguísticas analisadas não são ortogonais entre si: Tipo de Relação e Intenção Comunicativa. Não há, por exemplo, combinação da variante ordenar com a relação assimétrica. Por não haver todas as combinações possíveis entre elas, foram realizados dois modelos de regressão logística de efeitos mistos: no modelo 1, incluiu-se a variável Tipo de Relação e excluiu-se Intenção Comunicativa da análise e, no modelo 2, inversamente incluiu-se a variável Intenção Comunicativa e excluiu-se Tipo de Relação. Todas as demais variáveis previsoras foram incluídas em ambos os modelos. Veja-se os resultados a seguir.

\subsection{Variáveis previsoras sociais}

Na Tabela 3 a seguir, são apresentados os resultados das análises da regressão logística em modelo de efeitos mistos acerca do uso do imperativo associado ao indicativo pelos migrantes residentes em São Paulo, com base nas variáveis previsoras sociais Escolaridade, Idade de Migração, Tipo de Relação e Tempo em São Paulo.

Tabela 3 - Resultados das análises de regressão logística em modelos de efeitos mistos para o uso do imperativo com morfologia de indicativo para as variáveis previsoras sociais.

\begin{tabular}{lccccc}
\hline \hline & Estimativa & Erro padrão & Valor- $z$ & $p$ & \\
\hline Intercept) & 0,194389 & 0,001541 & 126,2 & $<0,001$ & $* * *$ \\
\hline Escolaridade & & & & & \\
Nível Superior & $-1,238872$ & 0,001540 & $-804,3$ & $<0,001$ & $* * *$ \\
\hline Idade de Migração & & & & & \\
Faixa II (22 - 24 anos) & 1,124633 & 0,001540 & 730,3 & $<0,001$ & $* * *$ \\
Faixa III (25 - 35 anos) & 0,190129 & 0,001540 & 123,5 & $<0,001$ & $* * *$ \\
\hline Tipo de Relação & & & & & \\
Simétrica & $-0,457569$ & 0,001540 & $-297,1$ & $<0,001$ & $* * *$ \\
\hline
\end{tabular}




\section{Tempo em São Paulo}

$\begin{array}{llllll}\text { Faixa II }(8-15 \text { anos }) & -0,953091 & 0,001540 & -618,8 & <0,001 & * * * \\ \text { Faixa III ( } \geq 16 \text { anos }) & -1,142515 & 0,001540 & -741,9 & <0,001 & * * *\end{array}$

Modelo1: glmer(VD ESCOLARIDADE + TIPO.RELACAO + IDADE.MIGRACAO + TEMPO.SP + POLARIDADE + CONTEXTO + (1 I INFORMANTE $)+(1$ I VERBO $)$, data: dadosSP $)$ Intercept $=$ Até o Nível Médio, Faixa I (13 - 21 anos), Assimétrica, Faixa I ( $0-7$ anos). Fonte: elaborado pelo autor.

Para a variável Escolaridade, a estimativa negativa da variante nível superior (1.238872), em relação ao intercept (até o nível médio), indica que os falantes mais escolarizados usam menos o imperativo associado ao indicativo em comparação aos que são menos escolarizados. Esse resultado segue a direção do estudo de Alves (1979) que, ao avaliar as atitudes linguísticas de 116 migrantes pernambucanos e baianos em São Paulo, no final da década de 1970, aventou a hipótese, a mesma utilizada aqui, de que os falantes que têm nível sociocultural baixo $^{7}$, por terem atitudes positivas para com o dialeto da comunidade anfitriã, tenderiam a assimilar mais os traços prototípicos dela em comparação com os falantes de nível sociocultural alto.

Por outro lado, chama atenção o fato de essa variável previsora não ter sido significativa em grande maioria dos estudos sobre a fala de migrantes, mas ter tido correlação com o uso do imperativo com forma de indicativo. Um possível motivo para os migrantes de nível de escolaridade baixa usarem mais essa variante é a existência, na comunidade paulista, de significados sociais vinculados à forma subjuntiva (FIGUEREIDO, 2017) ${ }^{8}$, variante prototípica da Bahia, cuja avaliação negativa, quiçá, tenha correlação com os indivíduos de baixo nível cultural.

Para Idade de Migração, as estimativas para os falantes que chegaram entre 22 24 anos (1.124633) e entre 25 - 35 anos (0.190129) mostraram-se favorecedoras para o

\footnotetext{
${ }^{7}$ Os termos "nível sociocultural alto" e "sociocultural baixo" são usados por Alves (1979).

${ }^{8}$ Agradeço a Joana Figuereido por ceder os slides do trabalho apresentado no III MiniEnapol, realizado na Universidade Estadual de Campinas - Unicamp, em 2017.
} 
imperativo associado ao indicativo, em relação a quem chegou entre 13 - 21 anos. Esse dado permite descartar a hipótese proposta para essa variável, a de que os migrantes que chegaram mais cedo a São Paulo assimilariam mais a forma indicativa em comparação aos que chegaram depois.

A diferença entre os logodds das faixas I, II e III permite acatar as hipóteses levantadas por Chambers (1992), ao analisar a aquisição dialetal de 6 canadenses que migraram para o Sul de Londres em 1983 e 1984. O autor considera que os traços morfológicos tenderiam a ser rapidamente assimilados pelos que chegaram à comunidade anfitriã tardiamente (adolescentes e adultos) em comparação aos traços fonéticos, que seriam mais facilmente adquiridos pelos que chegaram mais cedo (crianças).

Pessoas que se enquadram na faixa de idade de migração entre 22 - 35 anos, comumente, são aquelas que chegam a São Paulo para trabalhar e, talvez por pressão do mercado de trabalho (LABOV, 1972; BOURDIEU, 2008), o uso do imperativo associado ao indicativo tenha se tornado mais frequente. Segundo Brown e Levinson (1987), no inglês, a expressão imperativa You take that out! é avaliada como agressivamente rude em relação a Take that out! 'Leve isso pra fora!'. De modo semelhante, pode ser que, em certas variedades do português, como a paulista, a forma de indicativo seja avaliada como mais polida em relação à forma subjuntiva (SCHERRE, 2003, 2004; OLIVEIRA, 2017; FIGUEREIDO, 2017) e, por conta disso, os migrantes baianos adultos tenham tido maior necessidade de se adaptar quanto ao uso da variante prototípica da comunidade anfitriã.

Para Tipo de Relação, o valor de -0.457569 para a relação simétrica, em relação a assimétrica, indica que a morfologia de indicativo tem menos chances de ocorrer nas 
situações em que os interlocutores não se diferenciam hierarquicamente ${ }^{9}$, como em (1j). Esse favorecimento, talvez, tenha a ver com o tipo de profissão que os migrantes têm em São Paulo. É plausível que haja alguma diferença do uso da forma imperativa entre aqueles falantes que trabalham em setores de atendimento ao público e aqueles que trabalham em serviços gerais, como domésticas, copeiros, cozinheiros e outros. Pelo fato de o corpus ser limitado quanto a informações acerca dos participantes, a correlação entre o uso do imperativo e o tipo de profissão não pôde ser testada, mas é algo a ser observado em análises futuras, sobretudo para estudo dessa variável sociolinguística.

Se se assumir que há essa diferença, pode-se conjecturar que migrantes que mantêm contato com pessoas desconhecidas, por exemplo, os que trabalham no comércio, em que, a todo momento, precisam usar formas imperativas com o intuito de convencer os clientes a comprar os produtos, usariam a forma indicativa a fim de deixar o enunciado menos impositivo; mas sendo aqueles que têm uma profissão restrita aos ambientes fechados ou familiares, nos quais há grande probabilidade de eles criarem laços afetivos, como uma empregada doméstica, por exemplo, o uso da forma indicativa seria mais recorrente em contextos em que fossem evocadas atitudes solidárias.

As estimativas negativas das duas últimas faixas de Tempo em São Paulo (8 - 15 anos: -0.953091 e $\geq 16$ anos: -1.142515) mostram que a faixa I ( 0 - 7 anos) é favorecedora do uso do imperativo com morfologia de indicativo pelos baianos em São Paulo em relação a quem está na comunidade há mais tempo. Esse dado contraria a hipótese aventada para essa variável, a de que quanto mais tempo o migrante estiver na comunidade anfitriã, mais formas indicativas ele usaria. Além disso, chama atenção a

${ }^{9}$ É possível que haja alguma correlação entre as formas imperativas e o uso dos pronomes de $2^{\underline{a}}$ pessoa, como tu/você. Para análises futuras, recomenda-se o cruzamento dessas duas variáveis sociolinguísticas. 
diferença dos logodds entre a faixa II ( 8 - 15 anos) e a III ( $\geq 16$ anos). O valor de -0.953091 da faixa II em comparação à faixa III (-1.142515) sugere que os indivíduos dessa última faixa usam ainda menos o imperativo com morfologia de indicativo em comparação com os informantes da faixa II. Esses dados sugerem que os migrantes, quando chegam a São Paulo, acomodam-se (GILES et al., 1973) aos seus pares e convergem ao dialeto paulista quanto ao uso do imperativo com morfologia de indicativo, talvez por uma atitude positiva, conforme propunha Alves (1979), ou por causa dos significados sociais imbricados à forma imperativa com morfologia de subjuntivo, variante prototípica da comunidade nativa dos migrantes baianos, avaliada, muitas vezes, como uma forma ríspida (OLIVEIRA, 2017).

Se se assumir que o aumento do uso do imperativo associado ao indicativo tenha ocorrido dessa maneira, seria possível inferir também que, à medida que o tempo passasse, os migrantes se integrariam à comunidade anfitriã e, por causa disso, haveria um "relaxamento linguístico" da parte deles, ou seja, talvez a ideia de rispidez começasse a ser descontruída e o migrante sentisse à vontade para usar a forma prototípica de sua gramática nativa.

\subsection{Variáveis previsoras linguísticas}

As variáveis linguísticas, a grande maioria de cunho pragmático, permitem estimar como os migrantes se comportam linguisticamente quanto ao uso do imperativo associado ao indicativo durante uma interação na comunidade anfitriã. Os resultados mostram qual das formas imperativas os migrantes reportaram usar durante a intenção comunicativa de aconselhar, instruir, pedir e ordenar; no contexto temporal imediato ou não-imediato em que a ação deve ser realizada por parte do locutário; e a polaridade da ação demandada, se afirmativa ou negativa. Vejam-se os valores em logodds na Tabela 4. 
Tabela 4 - Resultados das análises de regressão logística em modelos de efeitos mistos para o uso do imperativo com morfologia de indicativo a partir das variáveis linguísticas.

\begin{tabular}{lccccc}
\hline & Estimativa & Erro padrão & Valor- $z$ & $P$ & \\
\hline Intercept $)$ & 0,041170 & 0,001507 & 27,33 & $<0,001$ & $* * *$ \\
\hline Intenção Comunicativa & & & & & \\
Instruir & 0,112044 & 0,001506 & 74,40 & $<0,001$ & $* * *$ \\
Pedir & 0,210153 & 0,001555 & 135,12 & $<0,001$ & $* * *$ \\
Ordenar & 0,112965 & 0,001506 & 75,01 & $<0,001$ & $* * *$ \\
\hline Contexto Temporal & & & & & \\
Não imediato & $-0,314246$ & 0,001506 & $-208,61$ & $<0,001$ & $* * *$ \\
\hline Polaridade & & & & & \\
Negativa & $-0,730538$ & 0,001506 & $-484,93$ & $<0,001$ & $* * *$ \\
\hline Intenção * Escolaridade & & & & & \\
Instruir * Nível Superior & 0,650998 & 0,001506 & 432,29 & $<0,001$ & $* * *$ \\
Pedir * Nível Superior & 0,512422 & 0,001506 & 340,27 & $<0,001$ & $* * *$ \\
Ordenar * Nível Superior & $-0,889006$ & 0,001506 & $-590,27$ & $<0,001$ & $* * *$ \\
\hline \hline
\end{tabular}

Modelo2: glmer (VD ESCOLARIDADE * INTENCAO + IDADE.MIGRACAO + TEMPO.SP + POLARIDADE + CONTEXTO + (1 I INFORMANTE $)+(1$ । VERBO $)$, data: dadosSP $)$ Intercept $=$ Aconselhar, Imediato, Afirmativa.

Fonte: elaborado pelo autor.

Para melhor compreender o resultado do uso do imperativo com morfologia de indicativo quanto à Intenção Comunicativa dos migrantes baianos em São Paulo, observam-se as proporções de indicativo para os níveis dessa variável (Figura 1). 
Figura 1 - Proporções de uso do imperativo com morfologia de indicativo por Intenção Comunicativa, nos dados de migrantes baianos em São Paulo.

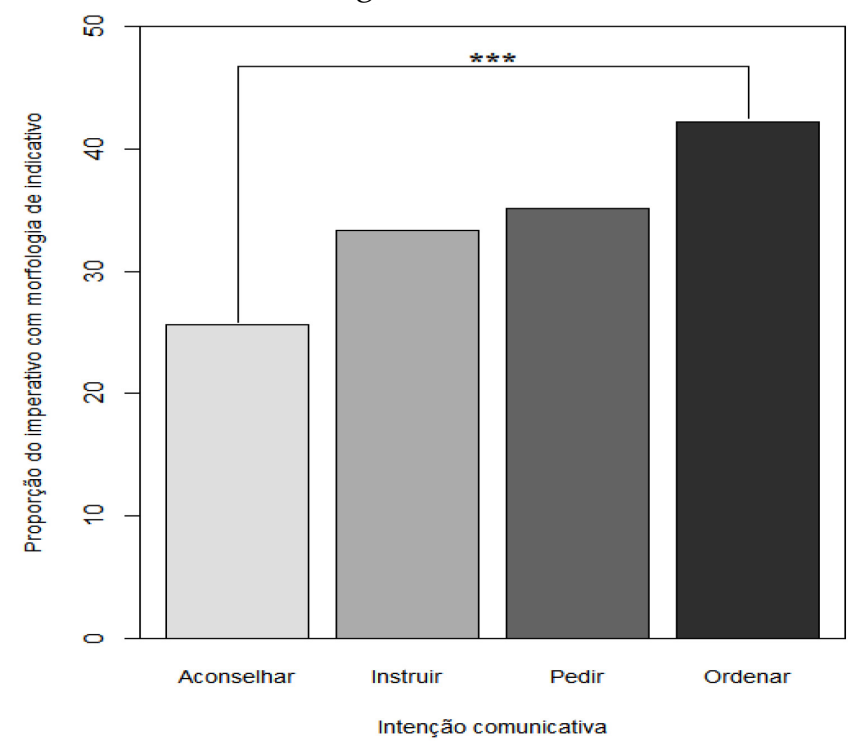

Fonte: elaborado pelo autor.

A Figura 1 mostra que o imperativo com morfologia de indicativo, em relação à forma subjuntiva, ocorreu na intenção comunicativa de aconselhar em $26 \%$ das ocorrências imperativas; de instruir em 33 \%; de pedir em 35 \%; e ordenar em 42 \%. Pelo fato de essa variante ter apresentado o maior valor percentual comparado às demais, esperava-se que o seu valor em logodds $(0,112965)$ também fosse superior aos outros coeficientes dos níveis dessa variável. Contudo, não é isso que se verifica na Tabela 4, em que a intenção de pedir apresenta maior valor de logodds $(0,210153)$. Essa diferença dá indícios de essa variável interagir com outra analisada no modelo, ou seja, o uso do imperativo com morfologia de indicativo é motivado pela intenção comunicativa face outra variável, conforme se verá mais adiante.

Os valores percentuais de cada variante da intenção comunicativa configuram um continuum pragmático, cujas intenções podem ser classificadas, sob a perspectiva do locutário, desde uma situação [- tensa] até uma [+ tensa]. Naquela primeira situação, o indivíduo, ao ouvir a forma imperativa, não entende a declaração como uma obrigação a ser cumprida; tal é o caso de interações com a intuito de aconselhar, como nos exemplos (2a) e (2b), aqui reproduzidos de (1n) e (1o). Por outro lado, na situação [+ 
tensa], ao ouvir a forma imperativa, o locutário percebe a necessidade de realizar a ação imposta, como acontece, por exemplo, numa situação de ordem (2c).

(2)

a. Sua amiga tirou carteira de $\rightarrow$ habilitação e está prestes a viajar, mas tem muito medo de dirigir em uma BR. Que conselho lhe daria?

b. Sua amiga se preocupa muito com a opinião das outras pessoas e, por isso, evita fazer coisas que a sociedade condene. Que conselho você daria para ela?

c. Você é um professor que não tolera atrasos e um aluno chega 30 minutos após a aula ter começado. O que diria a ele?
- Pense que está em uma via calma e tudo vai ficar bem.

- Pensa que está em uma via calma e tudo vai ficar bem.

- A vida é curta! Dá menos importância pra essas pessoas!

- A vida é curta! Dê menos importância pra essas pessoas!

- Não entra na sala, espera a próxima aula começar!

- Não entre na sala, espere a próxima aula começar!

Durante um aconselhamento, como em (2a) e (2b), o locutor considera as preocupações pelas quais o seu locutário passa e usa as formas imperativas associadas a outros fatores linguísticos que denotem brandura, como, por exemplo, o uso de expressões atenuantes como "tudo vai ficar bem" (2a), a utilização de argumentos como "a vida é curta" (2b) e, em circunstâncias de fala, o timbre de voz suave e a fisionomia pacifista.

A intenção de instruir teve o coeficiente $(0,112044)$ um pouco maior em comparação ao de aconselhar, menor em relação ao de pedir $(0,210153)$ e ocupa uma posição [+/- tensa] no continuum pragmático. Essa intenção pode ser vista como [+/tensa], porque ela depende de outros fatores, como, por exemplo, o tipo de relação com o interlocutor (se simétrica ou assimétrica) e a presença/ausência de expressões atenuantes, para ser entendida como impositiva ou não. Pelo fato de as variáveis não 
serem ortogonais, não se pôde testar a interação entre as variáveis Intenção Comunicativa e o Tipo de Relação. Logo é algo que carece de atenção em análises futuras.

Durante uma instrução, a depender do tipo de relação com o interlocutor, o locutor pode, além de empregar expressões que minimizem a dificuldade de o instruído aprender algo, como o excerto "filha, é fácil" em (3a), usar o imperativo com morfologia de indicativo a fim de diminuir o distanciamento entre ele e o seu locutário e, consequentemente, impedir que essa ação imperativa se assemelhe a uma imposição, por isso ser considerada uma intenção [+/-tensa].

(3)

a. Julia se casou e é péssima na $\rightarrow \quad \circ \quad$ Filha, é fácil! Coloca o arroz em cozinha. Então ela pede ajuda à mãe dela para preparar um simples arroz. Se você fosse a mãe de Julia, com ensinaria? uma panela com água e sal e espera cozinhar.

- Filha, é fácil! Coloque o arroz em uma panela com água e sal e espere cozinhar.

Os resultados da Tabela 4 evidenciam uma polarização pragmática a respeito do uso do imperativo com morfologia de indicativo: quanto mais distante da intenção de ordenar (como é o caso de aconselhar), menor será a chance de o migrante usar o imperativo com morfologia de indicativo; quanto mais próximo de ordenar (como é o caso de pedir), maior a probabilidade de usá-lo, justamente para que o ato de pedir não seja entendido como uma imposição

Para ilustrar essa interpretação, veja-se o exemplo em (4a). A cena denota uma relação profissional entre os interlocutores. O uso da expressão "por favor", nesta situação, foi intencionado para denotar um pedido. Neste caso, é possível que a forma indicativa tenha sido preferida com o propósito de não passar uma ideia de imposição ao funcionário. 
(4)

a. Você levou seu computador

- Por favor, não se esqueça de para formatar, mas só poderá formatar o meu computador. pegar dois dias depois. Você está com receio de o funcionário

- Por favor, não se esquece de formatar o meu computador. se esquecer de fazer o serviço. Como você diria para ele?

Seguindo o valor ascendente do logodds de pedir (0,210153), em comparação a instruir $(0,112044)$, a expectativa era a de que a variante ordenar tivesse o coeficiente mais alto em relação a essas variantes, uma vez que ela mostrou o total de $42 \%$ de realizações da forma indicativa (Figura 1), em proporção à forma subjuntiva. O seu valor em logodds indica que essa variável interage com outra. O modelo de regressão logística indicou haver a interação entre Intenção Comunicativa e Escolaridade (ver Tabela 4). A Figura 2 a seguir expõe a interação entre essas variáveis.

Figura 2 - Gráfico de interação entre as variáveis Intenção Comunicativa e Escolaridade na análise de regressão logística em modelo de efeitos mistos para o uso do imperativo com morfologia de indicativo por migrantes baianos em São Paulo.

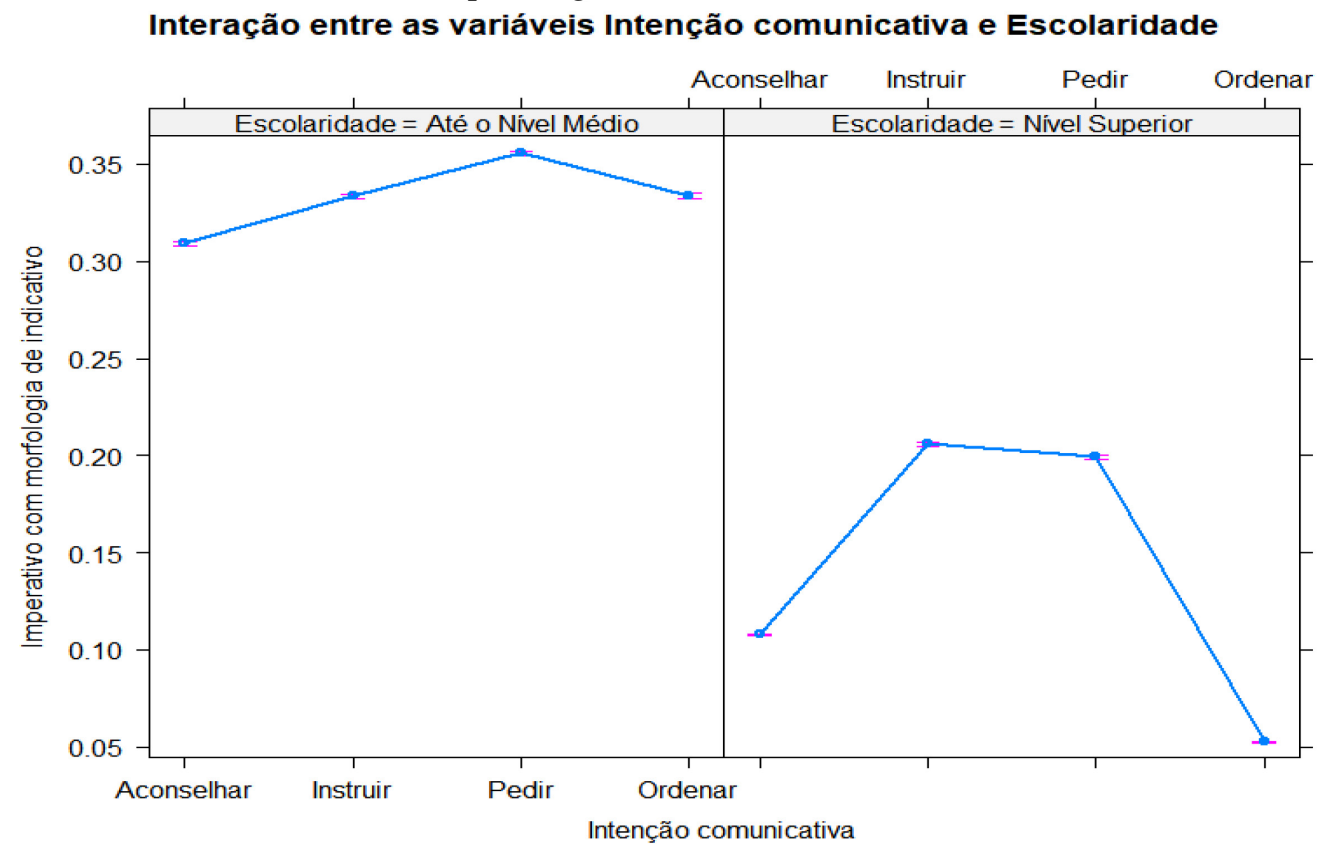

Fonte: elaborado pelo autor. 
A Figura 2 compara a aplicação do imperativo com morfologia de indicativo pelos informantes que têm até o nível médio (à esquerda) e por aqueles que têm o nível superior (à direita) quando a intenção comunicativa é de aconselhar, instruir, pedir e ordenar. De acordo com o gráfico, ambos os níveis de escolaridade empregam menos a forma de indicativo, em relação à forma de subjuntivo, nos quatro contextos, como se vê pelas proporções abaixo de $50 \%$.

No padrão dos informantes com até o nível médio, nota-se uma progressão ascendente do uso do indicativo da intenção de aconselhar até pedir e um declínio dessa variante até a intenção de ordenar. Já no padrão dos falantes de nível superior, a progressão do uso do indicativo é ascendente de aconselhar até instruir e pedir, declivando dessas variantes até a intenção de ordenar.

A interação entre a intenção comunicativa e a escolaridade do participante revela que há uma distinção entre o padrão de uso do imperativo com morfologia de indicativo entre os falantes que têm até o nível médio e os que têm nível superior. Com o padrão dos indivíduos que têm até o nível médio, acata-se a hipótese levantada para essa variável, a de que as intenções de ordenar e pedir favoreceriam mais o imperativo com morfologia de indicativo, em relação a aconselhar e instruir.

Além disso, essa diferença sustenta a hipótese de que há significados sociais negativos acerca do uso da forma subjuntiva por indivíduos de baixo nível de escolarização. Por outro lado, para os participantes de nível superior, diferentemente do que ocorre para aqueles de nível médio, a intenção de ordenar desfavorece fortemente o uso do indicativo, sendo o subjuntivo usado quase que categoricamente nesse caso. Os diferentes padrões de uso das variantes do imperativo por parte de falantes com diferentes níveis de escolaridade sugerem que os significados sociais associados a cada variante não são os mesmos para esses grupos.

Para o Contexto Temporal, a estimativa negativa da variante não imediato (0,314246) mostra que a forma de imperativo associada ao indicativo tem menor 
probabilidade de acontecer quando a ação demandada deve se concretizar no futuro não imediato, como em (5a), diferentemente de (5b), cuja ação deve ser realizada naquele exato momento. Com isso, acata-se a hipótese alternativa proposta para essa variável, de que os contextos imediatos favoreceriam o uso da forma indicativa. Esse resultado segue na mesma direção daqueles obtidos para essa variável no trabalho realizado por Nunes e Schwenter (2015), que chegaram à conclusão de que as ações não imediatas $(2,2248)$ favorecem o uso do imperativo com morfologia de subjuntivo.

\begin{tabular}{|c|c|c|c|}
\hline $\begin{array}{l}\text { a. Você se esqueceu de comprar } \\
\text { os ovos para fazer o bolo e }\end{array}$ & $\rightarrow$ & 0 & $\begin{array}{l}\text { Quando vier pra casa, compre ovos } \\
\text { pro bolo. }\end{array}$ \\
\hline $\begin{array}{l}\text { lembra que seu filho está na rua. } \\
\text { Ao ligar pra ele, como você } \\
\text { pediria pra ele trazer? }\end{array}$ & & ○ & $\begin{array}{l}\text { Quando vier pra casa, compra ovos } \\
\text { pro bolo. }\end{array}$ \\
\hline $\begin{array}{l}\text { b. O pai percebe que o filho está } \\
\text { mexendo no celular em vez de }\end{array}$ & $\rightarrow$ & 0 & $\begin{array}{l}\text { Faça as atividades ou vou tomar } \\
\text { seu celular. }\end{array}$ \\
\hline $\begin{array}{l}\text { fazer as atividades escolares. Se } \\
\text { você fosse o pai, o que diria para }\end{array}$ & & 0 & $\begin{array}{l}\text { Faz as atividades ou vou tomar seu } \\
\text { celular. }\end{array}$ \\
\hline
\end{tabular}
seu filho?

Para a variável Polaridade, o valor de -0,730538 da variante polaridade negativa, em comparação ao intercept (afirmativa), indica que a forma indicativa tende a não acontecer em sentenças negativas, como o excerto (6a), em relação às frases afirmativas, como o exemplo em (6b). Esse resultado indica que a hipótese alternativa de que as sentenças afirmativas motivariam a realização da forma indicativa deve ser considerada.

(6)
a. Você está estudando com seu
- Não deixe o cabeçalho em branco.
filho para uma prova amanhã.
- Não deixa o cabeçalho em branco.
Como você diria para ele não se esquecer de preencher $\mathrm{o}$ cabeçalho? 
b. Vocêé um(a) professor(a) que $\rightarrow$ solicitou aos alunos uma maquete como atividade avaliativa da unidade, mas um aluno esqueceu de trazê-la.
- Traz a maquete na próxima semana ou vai ficar com zero.

- Traga a maquete na próxima semana ou vai ficar com zero.

O resultado para essa variável segue o padrão encontrado por Oliveira (2017, p. 36) que, ao analisar os dados das capitais do Nordeste a partir do corpus do ALiB (CARDOSO et al., 2014), nota o favorecimento da polaridade afirmativa para com o uso do imperativo associado ao indicativo, com o peso relativo de 0,533 . Na literatura sobre o uso das formas de imperativo, esse padrão tem sido recorrente (ver Scherre 2003).

\section{Considerações finais}

A presente pesquisa teve como principal questionamento saber se os migrantes baianos residentes em São Paulo aumentariam a proporção de uso do imperativo com morfologia de indicativo ao manter contato com a comunidade anfitriã; em caso positivo, buscou-se investigar em quais contextos esse aumento tende a ocorrer. $\mathrm{O}$ resultado do cotejo do uso da forma indicativa por baianos na Bahia e por migrantes baianos em São Paulo mostrou que essa comunidade tende a usar mais forma indicativa (34 \%) em relação àquela (23 \%). O resultado da regressão logística aplicada a esses dados apontou que essa diferença é significativa $(p<0,05)$, logo pode-se inferir que o aumento da proporção de uso da forma indicativa pelos migrantes baianos tenha ocorrido, possivelmente, por causa do contato dialetal com os paulistas.

Em virtude da ausência de ortogonalidade entre as variáveis Tipo de Relação e Intenção Comunicativa, realizaram-se dois modelos estatísticos de regressão logística de efeitos mistos com inclusão do Informante e do Verbo como variáveis aleatórias. No primeiro modelo, incluiu-se a variável Tipo de Relação e excluiu-se a Intenção Comunicativa, enquanto, no segundo, fez-se o contrário. 
As análises da regressão logística de efeitos mistos das variáveis previsoras sociais sugerem que o aumento do uso do imperativo com morfologia de indicativo por migrantes baianos em São Paulo tende a ocorrer na fala de migrantes que têm até o nível médio em relação aos que possuem o nível superior (-1,238872); por aqueles que chegaram à comunidade anfitriã com idade entre $22-24$ anos $(1,124633)$ e 25 - 35 anos (0,190129), em comparação aos que chegaram entre 13 - 21 anos; em relações assimétricas em relação às simétricas (-0,457569); e por aqueles que estão em São Paulo entre 0 - 7 anos, em relação aos que estão há mais tempo, entre $8-15$ anos $(-0,953091)$ e há mais de 16 anos $(-1,142515)$.

Já as análises das variáveis previsoras linguísticas indicam que a realização da forma indicativa dos migrantes baianos em São Paulo tende a ocorrer em contextos pragmáticos nos quais os falantes têm a intenção comunicativa de pedir $(0,210153)$ e de ordenar $(0,112965)$, em relação a instruir $(0,112044)$ e a aconselhar; em demandas a ser realizadas em situações imediatas em comparação a não imediatas (-0,314246); e em frases afirmativas em relação a negativas $(-0,730538)$. Para análises futuras, sugerese testar a correlação entre o uso das formas imperativas com o tipo de profissão dos informantes e também a interação entre as variáveis Tipo de Relação e Intenção Comunicativa.

O resultado geral desta pesquisa coaduna com o trabalho de Cardoso (2009) sobre a mudança no comportamento linguístico de migrantes causada pelo contato dialetal. Na análise das variáveis previsoras sociais, os resultados sustentam a hipótese de Alves (1979) de que, em situações de contato dialetal, os falantes menos escolarizados tendem a adquirir os traços da comunidade anfitriã em comparação aos mais escolarizados; reforça a hipótese de Chambers (1992), de que, na mudança linguística gerada pelo contato dialetal, as variáveis morfossintáticas são mais facilmente assimiladas por adultos, em relação às variáveis fonéticas; refuta a hipótese de Oushiro (2017a), de que, quanto mais cedo o migrante chegar à comunidade 
anfitriã, mais traços linguísticos dela ele adquiriria; e segue na direção da hipótese de Dias (2007), de que o tipo de relação entre os interlocutores (simétrica ou assimétrica) pode influenciar o uso de uma variante em relação a outra.

No que diz respeito às variáveis linguísticas, de natureza pragmática, os dados aqui apresentados mostram a correlação entre o uso do imperativo com as intenções comunicativas (aconselhar, instruir, pedir e ordenar) e apontam a interação entre essa variável e o nível de escolaridade dos participantes. Ademais, os resultados sugerem que o aumento da proporção de uso do imperativo com forma de indicativo pelos migrantes baianos acontece nos mesmos contextos linguísticos de não migrantes em diferentes comunidades, como os padrões encontrados por Scherre $(2003,2004)$ e Oliveira $(2015,2017)$ quanto ao favorecimento da polaridade afirmativa para o uso da forma indicativa, e os apresentados por Nunes e Schwenter (2015) sobre o favorecimento do contexto imediato para o uso dessa variante.

\section{Referências Bibliográficas}

ALVES, M. I. P. M. Atitudes linguísticas de nordestinos em São Paulo. 1979. 226 f. Dissertação (Mestrado em Linguística). IEL/Unicamp, Campinas, 1979.

BOURDIEU, P. A economia das trocas linguísticas: o que falar quer dizer. 2. ed. Tradução de Sergio Miceli, Mary Amazonas Leite de Barros, Afrânio Catani, Denice Barbara Catani, Paula Montero, José Carlos Durand. São Paulo: EDUSP, 2008 [1996].

BROWN, P.; LEVINSON, S. Politeness: Some universals in language usage. New York: University of Cambridge, 1987. DOI https://doi.org/10.1017/CBO9780511813085

CARDOSO, D. B. B. Variação e mudança do imperativo no português brasileiro: gênero e identidade. 2009. 165 f. Tese (Doutorado em Linguística). Instituto de Letras, Universidade de Brasília, 2009.

CARDOSO, S. A. M. S. et al. Atlas linguístico do Brasil, v. 2. Londrina: EDUEL, 2014.

CHAMBERS, J. K. Dialect acquisition. Language, v. 68, n. 4, p. 673-705, 1992. DOI https://doi.org/10.1353/lan.1992.0060 
DIAS, E. P. O uso do tu no português brasiliense falado. Dissertação (Mestrado em Linguística). 2007. 114 f. Instituto de Letras, Universidade de Brasília, Brasília, 2007.

FIGUEREIDO, J. G. dos S. O estudo do modo imperativo nas cidades de Feira de Santana e Campinas: análises de produção e percepção. In: III MiniEnapol de Sociolinguística. Campinas: IEL/Unicamp, 2017.

FIGUEREIDO, J. G. dos S.; SOUZA, E. S. de. O uso do imperativo por migrantes baianos em São Paulo: um estudo comparativo. In: VII Encontro de Sociolinguística: Redes e Contato, Aracaju: Universidade Federal de Sergipe, 2017.

GILES, H.; TAYLOR, D.; BOURHIS, R. Toward a theory of interpersonal accommodation through speech: some Canadian data. Language in Society, v. 2, p. 177-192, 1973. DOI https://doi.org/10.1017/S0047404500000701

LABOV, W. The design of a sociolinguistic research project. In: Sociolinguistic Worshop. Mysore: Central Institute of Indian languages, 1972.

LEVSHINA, N. How to do Linguistics with R. Amsterdam: John Benjamins, 2015. DOI https://doi.org/10.1075/z.195

NUNES, L.; SCHWENTER, S. Variability in the form of southern Brazilian Portuguese imperatives. In: 44 NWAV. Toronto, 2015.

OLIVEIRA, J. M. de. A realização do imperativo gramatical nas capitais brasileiras: primeiros resultados. In: XII Workshop do Projeto Atlas Linguístico do Brasil. Salvador: UFBA, 2015.

OLIVEIRA J. M. de. O imperativo gramatical nas capitais do Nordeste: análise sociolinguística de dados do ALiB. In: LOPES, N. S.; OLIVEIRA, J. M.; PARCERO, L. M. J. (org.). Estudos sobre o português do Nordeste: língua, lugar e sociedade. São Paulo: Blucher, 2017. p. 27-44. DOI https://doi.org/10.5151/9788580392395-02

OUSHIRO, L. Projeto Processos de Acomodação Dialetal na Fala de Nordestinos Residentes em São Paulo. 2017a. Relatório Científico Parcial (FAPESP 2016/04960-7).

OUSHIRO L. Introdução à Estatística para Linguistas. v. 1.0 .1 (dez. 2017). 2017b. Disponível em: http://rpubs.com/oushiro/iel. Acesso: 29 maio 2018.

$\mathrm{R}$ Core Team. R: A language and environment for statistical computing. $R$ Foundation for Statistical Computing. Vienna, Austria, 2018. 
SCHERRE, M. M. P. Norma e uso na expressão do imperativo em revistas em quadrinhos da Turma da Mônica. In: SILVA, D. E. G. da; LARA, G. M. P.; MAGAZZO, M. A. (org.). Estudos de Linguagem - Inter-relações e Perspectivas. Campo Grande, Editora da UFMS. 2003. p. 177-191.

SCHERRE, M. M. P. Norma e uso - o imperativo gramatical no português brasileiro. In: DIETRICH, W.; NOLL, V. (org.). O português do Brasil - perspectivas da pesquisa atual. Iberoamericana/Vervuert, 2004, p. 231-260. DOI https://doi.org/10.31819/9783964562999-014

SIEGEL, J. Second dialect acquisition. New York: Cambridge University Press, 2010. DOI https://doi.org/10.1017/CBO9780511777820

THOMASON, S. G.; KAUFMAN, T. Language contact, creolization, and genetic linguistics. Los Angeles/Berkeley: University of California Press, 1988.

TRUDGILL, P. Dialects in contact. New York: Basil Blackwell, 1986.

WEINREICH, U. Languages in Contact: Findings and problems. Netherlands: Mouton Publishers. 1968 [1953].

WINFORD, D. Contact and borrowing. In: HICKEY, R. (ed.). The Handbook of Language Contact. Malden, MA: Wiley-Blackwell, 2010, p. 170-187. DOI https://doi.org/10.1002/9781444318159.ch8 